\title{
The Many Faces of Sleep Disorders in Post-Traumatic Stress Disorder: An Update on Clinical Features and Treatment
}

\author{
Franziska C. Weber Thomas C. Wetter \\ Department of Psychiatry and Psychotherapy, University of Regensburg, Regensburg, Germany
}

\section{Keywords}

Post-traumatic stress disorder - Sleep disorders .

Nightmares - Trauma-associated sleep disorder · Sleep- and nightmare-focused therapy

\begin{abstract}
Sleep disorders and nightmares are core symptoms of posttraumatic stress disorder (PTSD). The relationship seems to be bidirectional, and persistent disturbed sleep may influence the course of the disorder. With regard to sleep quality, insomnia and nocturnal anxiety symptoms, as well as nightmares and stressful dreams, are the most prominent sleep symptoms. Polysomnographic measurements reveal alterations of the sleep architecture and fragmentation of rapid eye movement sleep. In addition, sleep disorders, such as sleep-related breathing disorders and parasomnias are frequent comorbid conditions. The complex etiology and symptomatology of trauma-related sleep disorders with frequent psychiatric comorbidity require the application of multimodal treatment concepts, including psychological and pharmacological interventions. However, there is little empirical evidence on the effectiveness of long-term drug treatment for insomnia and nightmares. For nondrug inter-
\end{abstract}

(C) 2021 The Author(s)

Published by S. Karger AG, Basel

This is an Open Access article licensed under the Creative Commons Attribution-NonCommercial-4.0 International License (CC BY-NC) (http://www.karger.com/Services/OpenAccessLicense), applicable to the online version of the article only. Usage and distribution for commercial purposes requires written permission. ventions, challenges arise from the current lack of PTSDtreatment concepts integrating sleep- and trauma-focused therapies. Effective therapy for sleep disturbances may consequently also improve well-being during the day and probably even the course of PTSD. Whether early sleep interventions exert a preventive effect on the development of PTSD remains to be clarified in future studies.

(c) 2021 The Author(s).

Published by S. Karger AG, Basel

\section{Introduction}

For more than 3 decades, sleep disorders have been classified among the core symptoms of post-traumatic stress disorder (PTSD) [1]. According to the DSM-5 criteria, a diagnosis of PTSD requires exposure to a traumatic event of catastrophic intensity or an extraordinary threat [2]. In addition, the symptomatology of PTSD is conceptualized within the framework of 4 symptom clusters, with nightmares being classified as an "intrusion symptom" and insomnia as an "alteration in arousal and reactivity." Typically, symptoms occur with a latency of several weeks to months after the trauma. The present review provides an updated overview of the characteris- 
tics of sleep disorders related to PTSD and traumatization, including an overview of psychological and pharmacological interventions. Moreover, it highlights the significance of sleep disorders as important therapeutic target symptoms and also as risk and prognostic factors of PTSD.

\section{Bidirectional Relationship}

Studies in recent years have expanded upon the classic model of PTSD; namely in considering sleep disorders as symptoms of PTSD insofar as sleep seems to be of major importance regarding the development and course of the disorder. This relationship between PTSD and sleep disorders is suggested to be bidirectional [3]. It has also been shown that pretraumatically disturbed sleep may be a risk factor for later developing PTSD [4-7]. In addition, insomnia symptoms that occur immediately after a trauma may be predictive for PTSD $[8$, 9]. Pronounced sleep disturbances in PTSD also represent an important prognostic factor for the outcome, as they may increase the severity of the condition and thus, significantly impair quality of life and daily functioning [10], in addition to increasing risk of alcohol and drug misuse [11]. Disturbed sleep may also persist despite the improvement of other PTSD symptoms [12-14], which may promote the maintenance of PTSD over the course of the disorder $[15,16]$. Conversely, effective treatment of sleep disorders and nightmares may lead to a clinically significant decrease in PTSD symptoms during the day [17-19]. A recent study reported that in individuals with PTSD, sleep duration, trouble falling asleep, and difficulties staying asleep the prior night predict PTSD symptom severity the next day [20]. Accordingly, interventions that enable people to sleep better are likely to be of particular therapeutic importance, as they may have an immediate remedial effect on PTSD symptoms.

\section{Subjective Sleep}

Current epidemiological studies suggest that over 90\% of patients with PTSD suffer from clinically relevant sleep disorders [21]. In particular, difficulties falling and staying asleep as well as post-traumatic nightmares lead to irritability and exhaustion during the day and can impair emotional processing [22]. In addition, fear of the dark, lying awake at night ruminating about the trauma [23], talking or screaming during sleep, and waking up disorientated may also frequently occur [3].

\section{Insomnia}

Insomnia symptoms, that is, difficulty initiating or maintaining sleep is reported in 35-61\% of patients with PTSD; various factors such as comorbidities, different criteria for insomnia diagnosis across classification systems, or trauma type may influence the broad range of prevalence estimates [24]. PTSD often leads to acute insomnia with behavioral and cognitive symptoms. Perpetuating factors (e.g., poor sleep hygiene) and a state of hyperarousal may contribute to the maintenance and exacerbation of insomnia [24]. Fear of sleep is thought to play an important role in the development and maintenance of trauma-associated insomnia in the context of PTSD and sleep disturbances [25]. According to a recent model by Werner et al. [25], PTSD symptoms such as negative beliefs about safety and loss of control or re-experiencing the trauma (including nightmares) increase the fear of sleep. The hyperarousal symptoms, including insomniac complaints, in turn favor the emergence of insomnia-related maladaptive processes and therefore, contribute to the maintenance of insomnia. Avoidance behavior is likely to contribute to the maladaptive processes of both pathways and thus, has an equally reinforcing influence [25]. Treatment of fear of sleep could be integrated into both trauma-focused and sleep-focused approaches [25]. It remains unclear whether treatment-resistant insomnia [12-14] may also be due to lack of adequate consideration of fear of sleep.

\section{Post-Traumatic Nightmares}

Frightening post-traumatic nightmares occur in up to $67 \%$ of patients with PTSD [26] and may have a significant effect on the emotional state the following day. The spectrum of post-traumatic dreams ranges from traumarelated dreams to nightmares in which the trauma is reexperienced [27]. The different subtypes are summarized in Table 1.

While nightmares without a traumatic cause typically occur in the second half of the night and are associated with longer rapid eye movement (REM) episodes, nightmares in PTSD can occur during both REM and nonREM sleep [28]. Physiological changes, such as increases or fluctuations in heart and respiratory rate, can lead to awakening if significantly pronounced, and these events are often associated with nightmare awakenings. Typically, affected patients are fully oriented quickly despite marked anxiety symptoms.
Weber/Wetter 
Table 1. Subtypes of post-traumatic nightmares (abbreviated [27])

\begin{tabular}{lll}
\hline Post-traumatic dream & Post-traumatic nightmare & $\begin{array}{l}\text { Nonreplicate post-traumatic nightmare } \\
\text { nightmare }\end{array}$ \\
\hline Trauma-related dream content & $\begin{array}{l}\text { Frightening dream that leads } \\
\text { to awakening }\end{array}$ & $\begin{array}{l}\text { Content can be trauma-related, but does } \\
\text { not represent the trauma }\end{array}$ \\
\hline
\end{tabular}

\section{Polysomnographic Findings}

Although video polysomnography (PSG) is not a standard diagnostic tool for PTSD-associated sleep disorders, it may be indicated for the diagnosis of comorbid-specific sleep disorders, such as sleep-related breathing disorders (SRBD) or parasomnia (e.g., a behavioral disorder in REM sleep) [29]. Compared to healthy controls, sleep studies in patients with PTSD show partially heterogeneous results in overall sleep continuity and sleep architecture depending on the time of the examination (acute vs. chronic PTSD), psychiatric comorbidities (especially major depression), and age. With respect to non-REM sleep, an increase in light sleep (stage 1) and a decrease in slow-wave sleep (SWS) may be found (overview in [30, 31]). More consistent alterations, however, are observed in REM sleep, characterized by a fragmentation with a higher number of transitions from REM sleep to stage 1 or awake state [32]. In addition, an increased REM sleep pressure - a shortening of REM latency (time between falling asleep and the first REM episode) and a higher REM density (number of rapid eye movements) - has been reported [30, 32].

The current body of research suggests that individuals with PTSD typically exhibit low parasympathetic tone during awake-resting states, resulting in an elevated mean heart rate (HR) and reduced cardiac reactivity. During sleep, however, increased sympathetic activation characteristically occurs in PTSD patients and is observed primarily during REM sleep, resulting in increased HR and decreased reactivity [33]. One older study demonstrated that altered nocturnal heart rate variability (HRV) was predictive of the development of PTSD in traumatized patients [34]. This relationship was confirmed in further studies and is now considered established [33]. In addition, a study has shown that pretraumatic pathological HRV increases the risk of developing PTSD after trauma [35]. One study showed that elevated autonomic nervous system arousal indexed by HR with PTSD might be specific to the early part of sleep and that PTSD is possibly associated with impairment in regulating autonomic nervous system activity related to REM sleep [36].

A promising approach for gaining insight into the underlying pathophysiological mechanisms of PTSD and disturbed sleep is the topographic spectral analysis of sleep EEG. A recent study demonstrated alterations in EEG spectral topologies during non-REM and REM sleep that correlated positively with nightmare activity and insomnia. Based on these findings, a spectral index was developed to differentiate between patients and controls, thus serving as a candidate biomarker [37]. Moreover, a strong correlation of sleep EEG coherence markers with the diagnosis and severity of PTSD has been reported [38]. Studies using high-density EEG markers have demonstrated reduced sleep depth indicated by reduced centro-parietal non-REM delta power and increased gamma power in the anterofrontal regions during both non-REM and REM sleep, indicating higharousal levels in patients with PTSD. These alterations were replicable across consecutive nights and subpopulations [39]. Similar findings were reported in a recent study on sleep and emotion processing in pediatric PTSD, revealing a marked decrease in slow-wave activity and an increase in EEG gamma power during non-REM sleep in the patient group compared to healthy controls. In addition, a correlation between slow-wave activity power and affective habituation was most significant in a frontal cluster, indicating the importance of SWS for emotional processing in adolescence [40]. Sleep spindles are associated with sleep protection and sleep-dependent memory consolidation [41]. Recent studies demonstrated alterations in sleep spindle frequency and interchannel phase differences possibly reflecting defective sensory-gating mechanisms and thalamocortical circuits in patients with PTSD $[42,43]$. It remains to be clarified whether these neurophysiological candidate biomarkers are suitable parameters for diagnosis or follow-up assessments under treatment. Interestingly, a study of idiopathic nightmares demonstrated that early childhood adversity was associated with adult nightmare severity 


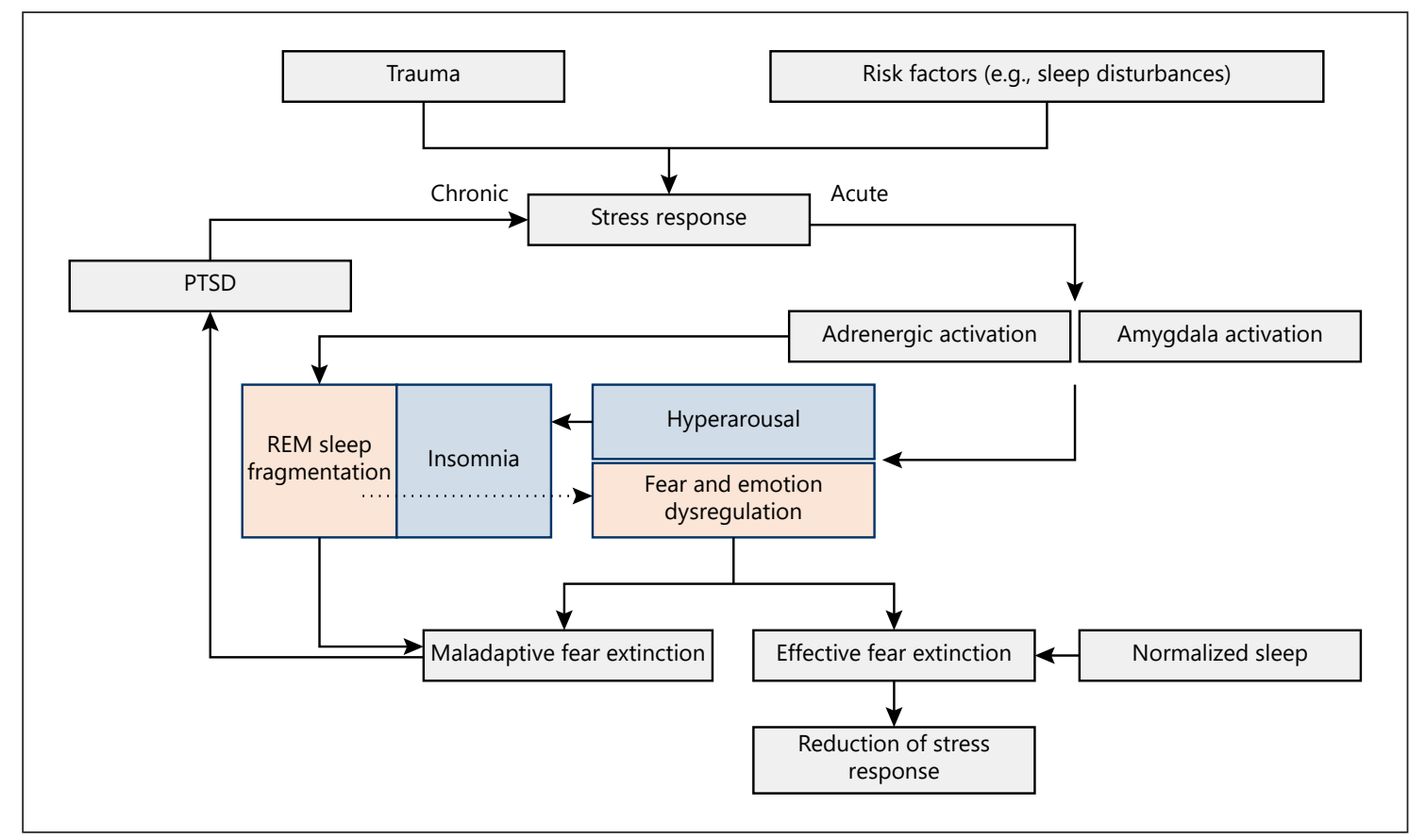

Fig. 1. Hypothesized interrelation between trauma, sleep disturbances, and PTSD. PTSD, post-traumatic stress disorder.

and disruption in basic sleep spindle expression, suggesting pathophysiological mechanisms similar to those of PTSD nightmares [44]. Blaskovich et al. [45] found an increased number of arousals in individuals with frequent nightmares, reflecting hyperarousal during preREM periods; the authors further emphasized that analyses of arousals should focus specifically on state transitory periods.

\section{Sleep and Emotion Regulation}

Sleep disturbances are thought to play a mechanistic role in the emotional memory and learning model of PTSD. This postulates maladaptive fear conditioning, extinction learning, extinction memory, and safety learning as central mechanisms of PTSD. Following a traumatic event, an acute stress response may lead to sleep disturbances that may facilitate fear learning. Efficient fear extinction results in a downscaling of the stress system. If these processes are maladaptive, a trauma may lead to PTSD. While healthy sleep promotes resilience, sleep disturbances favor the development and maintenance of PTSD [22] (Fig. 1). In animal studies in mice, it has been shown that trauma-associated sleep disturbances were as- sociated with electrophysiological parameters of impaired memory acquisition, consolidation, and recall [46], corroborating clinical findings.

Human and animal sleep studies indicate that REM sleep plays an essential role in the processing of emotional and traumatic events. It has been postulated that under the special neurochemical conditions of normal REM sleep (i.e., low adrenergic activity combined with high cholinergic activity), traumatic events are transformed into less stressful memory content (overview in [47]). This process is hypothesized to be altered in PTSD, as reflected by fragmented REM sleep. Accordingly, a recent functional MRI study showed that the amygdala responsiveness decreased proportionally to the duration of consolidated REM sleep, whereas experimentally induced "restless" REM sleep impaired amygdala adaptation in healthy subjects [48]. A constellation of fragmented REM sleep with excessive adrenergic neurotransmission and reduced activity of the medial prefrontal cortex may also lead to maladaptive consolidation of traumatic memory content [49] and promote the development of PTSD [22]. Acute REM sleep changes after stress exposure have also been demonstrated in rats. These changes were significantly correlated with impaired fear-associated memory processing and the onset of PTSD-like symptoms [50]. 
Table 2. Comorbid sleep disorders in PTSD

SRBD $[55,56]$

Nocturnal panic attacks [57-59]

Sleep terror [59]

RBD [60-64]

PLMD $[60,65]$

PTSD, post-traumatic stress disorder; REM, rapid eye movement; SRBD, sleep-related breathing disorder; RBD, REM sleep behavior disorder; PLMD, periodic limb movement disorder.

Recently, it has been reported that SWS may also play a role in adaptive emotional processing. In a study of children with PTSD, impairments in slow-wave activity were correlated with reduced affective habituation [40]. Especially in the field of emotion regulation and the neurobiology of processing traumatic memory content, experimental sleep research can provide new insights that aim at specific sleep interventions as preventive measures [51]. Animal studies have yielded mixed results; in a rodent model, optogenetically induced prolongation of sleep duration after trauma exposure led to a significant improvement in fear-associated memory processing, suggesting a beneficial effect on PTSD symptoms [52]. In contrast to these findings, prior studies in rodents provided evidence that preventing sleep in the early aftermath of trauma resulted in attenuated trauma stress responses $[53,54]$.

\section{Comorbid Sleep Disorders}

Apart from insomnia and nightmares, additional sleep disorders may frequently co-occur in patients with PTSD (Table 2). Factors mediating this association are largely unknown. Studies on the prevalence of SRBD and PTSD reveal highly mixed results. However, there is a concurrence that individuals with PTSD have a disproportionately higher rate of SRBD, such as upper airway resistance and obstructive sleep apnea syndrome (OSAS) than the general population [55]. Consequently, patients with PTSD are more likely to suffer from hypertension, dyslipidemia, and diabetes. It is hypothesized that post-traumatic sleep fragmentation adversely influences the airway and increases vulnerability to the subsequent development of OSAS, which in turn might worsen PTSD symptoms through further sleep fragmentation [55]. Accordingly, an association between effective OSAS treatment and reduced PTSD severity has been found $[66,67]$.

Sleep Disorders in Post-Traumatic Stress Disorder
Untreated OSAS may exacerbate sleep-related symptoms, including nightmares, insomnia, and daytime sleepiness. Interestingly, a recent study in otherwise healthy patients revealed that OSAS was associated with a significantly lower sleep spindle density in SWS and a shorter spindle duration in sleep stage 2 [68]. Given the changes in spindle characteristics in patients with PTSD, these findings support further investigations in the basic pathophysiological mechanisms underlying the association between SRBD and PTSD.

Previous studies have also reported that prevalence rates of REM sleep behavior disorder (RBD) are higher in psychiatric disorders in general [69] and particularly in PTSD [60-64]. RBD is characterized by violent dream enactment behavior due to a loss of REM sleep atonia. The underlying pathophysiology of this disorder remains unclear; however, the use of antidepressants altered neurotransmitter metabolism and intense nightmares may play a role [70]. The use of selective serotonin reuptake inhibitors (SSRIs) has been reported to be associated with REM sleep without atonia but not full-blown RBD [71]. Moreover, there is evidence that SSRIs can exacerbate REM sleep without atonia in psychiatric patients both with pre-existing RBD and without RBD [72]. The clinical significance of RBD symptoms in PTSD is undisputed [73], and a recent study has shown that their occurrence is an indicator for the consolidation of intrusive memories [74]. RBD, OSAS, and other comorbid sleep disorders, such as pavor nocturnus and nocturnal panic attacks, should be included in the differential diagnosis of nightmares, namely because the available specific treatment options may lead to a further improvement in sleep quality. Periodic limb movement disorder (PLMD) has also been found more frequently in patients with PTSD; however, the mechanism of this association remains unclear $[60,65]$. It has repeatedly been shown that serotonergic agents, such as Mirtazapine or SSRIs, which are also used to treat PTSD, can exacerbate or trigger PLMD $[75,76]$; however, systematic studies in the context of PTSD are lacking.

\section{Trauma-Associated Sleep Disorder}

First described in 2014, trauma-associated sleep disorder (TSD) is characterized by a constellation of parasomnia symptoms and is thought to result from a trauma without the presentation or development of full PTSD [77]. There is evidence that the time of traumatization (childhood vs. adolescence/adulthood) may influence the 
Table 3. Trauma-associated sleep disorder (obligatory criteria, abbreviated [27])

Onset after traumatic experiences

A history of altered dream mentation that is related to prior traumatic experience

Disruptive nocturnal behaviors, including at least abnormal vocalizations (e.g., yelling or screaming) or abnormal motor behaviors

(e.g., violent behavior in sleep)

Symptoms of autonomic hyperarousal or PSG monitoring (e.g., tachycardia and tachypnea)

PSG may demonstrate: RSWA or dream enactment behavior in REM sleep

Absence of epileptic EEG activity in PSG

PSG, polysomnography; REM, rapid eye movement; RSWA, REM sleep without atonia.

manifestation of sleep disorders (adulthood trauma is more likely to lead to nightmares, whereas childhood trauma is more likely to lead to acting out dreams) [78]. The obligatory diagnostic criteria postulated by Mysliwiec et al. [27] are summarized in Table 3.

Whether TSD is a separate pathology, remains under debate among experts [70, 73, 79]. Interestingly, TSD and RBD share some clinical features such as dream enacting behavior. However, the differential diagnosis of both disorders is important, as treatment with clonazepam is effective in RBD but not TSD [80]. Longitudinal studies are necessary to clarify whether TSD is consistently associated with loss of REM sleep atonia and to determine the risk of transition to neurodegenerative synucleinopathies [79].

\section{PTSD, Sleep, and Suicidality}

Chronic severe sleep disturbances and nightmares are a risk factor for suicidal behavior independently of any other comorbid mental illness [81]. The association of sleep disturbances with increased suicidality is seen in adolescents [82, 83] and the elderly [84]. Self-injurious behavior has also been linked to sleep disturbances [85], with these being thought to play a mediating role between PTSD and self-injury [86]. A recent systematic review concluded that both sleep disturbances, such as low sleep efficiency, and increased HR are associated with suicidality [87]. Autonomic dysfunction (including nocturnal symptoms), such as altered HR or HRV, is well established in the context of PTSD $[33,88]$. A study of traumatized individuals demonstrated that a standard index of autonomic activity (low-frequency/high-frequency ratios in the HRV index) was predictive of the extent of PTSD symptoms and also of suicidality [89]. On the other hand, PTSD is in itself a risk factor for suicidality [90, 91]. Although sleep disorders and PTSD are established risk fac- tors for suicidality and, conversely, the reciprocal influence of sleep and PTSD is well established, little is known about the complex interplay between sleep, PTSD, and suicidality. A recent review of the literature revealed inconsistent study results due to different patient demographics, target parameters, and methodological shortcomings [92]. A longitudinal study including a large number of US soldiers showed that insomnia before military service is predictive for the development of PTSD and suicidal thoughts after service [7]. However, when looking at all relevant studies, the question of an increased risk of suicidal behavior due to sleep disorders in the context of PTSD cannot be answered conclusively. This would, however, be of importance insofar as targeted treatment of sleep disorders and nightmares could contribute to reducing the risk of suicidality in PTSD patients [93].

\section{Treatment}

The primary goal of sleep- and nightmare-focused therapy is an effective reduction of nocturnal symptoms, which may also lead to an improvement in daytime wellbeing [17-19]. Similarly, trauma-focused therapy can also positively influence sleep-related symptoms [94], and synergistic effects can be achieved with regard to PTSD symptoms [26]. However, there is a lack of concepts in clinical practice that equally integrate day- and night-time symptoms into the treatment [95]. In particular, psychiatric comorbidities have to be taken into account for the development of multimodal therapy concepts.

\section{Psychotherapy}

The first choice of treatment for chronic insomnia is disorder-specific cognitive behavioral therapy for insomnia (CBT-I) [96, 97], comprising treatment modules that
Weber/Wetter 
Table 4. Cognitive behavioral therapy for insomnia (CBT-I)

\begin{tabular}{ll}
\hline Modules & Methods \\
\hline Psychoeducation & Information on sleep and sleep disorders; sleep hygiene recommendations \\
Relaxation techniques & Progressive muscle relaxation, mindfulness, yoga, and meditation \\
Sleep restriction & Limiting the amount of time spent in bed to an amount equal to sleep time \\
Stimulus control & Reconditioning the bed and bedroom as strong cues for sleep \\
Cognitive therapy & Cognitive restructuring of dysfunctional beliefs and attitudes about sleep \\
\hline
\end{tabular}

are also successfully used for PTSD-associated insomnia (Table 4) [98]. Effective techniques for the treatment of post-traumatic nightmares include Imagery Rehearsal Therapy (IRT) and Exposure, Relaxation, and Rescripting Therapy (ERRT), as well as Exposure Therapy and Eye Movement Desensitization and Reprocessing (EMDR) therapy. The basic principle of IRT is a modification of the nightmare into less stressful dream content. The patient replaces the traumatizing situation with new, positive images. The modified scenario is then practiced several times during the day in order to implement the new imaginative "script" in the dreams [99]. Meta-analyses suggest that IRT is the most effective treatment for post-traumatic and idiopathic nightmares $[26,100]$. IRT via the Internet seems to be similarly effective [101]. ERRT combines psychoeducational elements with imaginatively altered nightmares [102] and may also be effective in an abbreviated form [19]. It can also be used to treat residual nightmares after regular PTSD treatment [103]. In addition, ERRT was also shown to reduce suicidal ideation, although this effect did not remain after controlling for PTSD and depression [104]. Within the framework of exposure therapy, the traumatizing event is recalled in as much detail as possible under the guidance of a therapist and processed step by step [105]. EMDR therapy is characterized by bilateral sensory stimulation (induced eye movements and touching of the hands) while recalling distressing images; this stimulates new processing and integration of traumatic experiences, especially on a sensory-somatic level, which can lead to a reduction in the intensity of nightmares [106]. There is also a trend to combine different treatments and to develop therapies tailored to specific target groups. For example, in a case series of patients with PTSD, the combination of CBT-I and IRT was shown to be effective in treating nightmares and insomniac symptoms [107]. In a pilot study, the combination of CBT-I and prolonged exposure proved effective in reducing insomnia and PTSD [108]. Special therapy programs have been developed and successfully used for veterans with PTSD and depression

Sleep Disorders in Post-Traumatic Stress Disorder who had residual nightmares and insomnia [109]. Another example in this context is Firefighter's Therapy for Insomnia and Nightmares, which combines brief CBT-I with elements of IRT [110]. Lucid dreaming may also be used [111], but a reduction of PTSD-associated nightmares could not be demonstrated in a recent study [112]. The conclusiveness of this study, however, is limited due to various factors (i.e., low number of cases and high dropout rate). It is a great challenge to develop effective protocols for the induction of lucid dreaming, since only about $50 \%$ of all people have the basic ability to lucid dream, and only about $20 \%$ of them dream lucidly with some regularity [113].

\section{Pharmacotherapy}

In clinical practice, PTSD-associated insomnia is often treated using sedative antidepressants (e.g., mirtazapine, doxepin, trimipramine, and amitriptyline) or sedative atypical antipsychotics (e.g., quetiapine). However, the evidence is limited, given the small number of studies and the potential side effects, especially when treatment over a longer period is required [114-117]. Z-drugs (zolpidem and zopiclone) or benzodiazepines may be used in the short-term (2-4 weeks) treatment of insomnia [96]. Due to their addictive potential, these drugs should be used with caution, and long-term treatment should be avoided, especially considering that the risk of dependency seems to be increased in patients with PTSD [118]. Interestingly, an altered benzodiazepine receptor-binding profile in patients with PTSD has been reported in a functional neuroimaging study [119]. In the current guidelines of the American Academy of Sleep Medicine (AASM), single drugs are evaluated with regard to their efficacy and benefit-risk profile. No recommendation for single drugs in the treatment of insomnia is higher than "weak." A "weak" recommendation represents lower certainty in the appropriateness of the treatment strategy for all patients, but this is not an indicator of ineffectiveness [120]. Among antidepressants, only doxepin and trazodone are evaluated in the guidelines; quetiapine is the 
Table 5. Pharmacological treatment of post-traumatic nightmares*

\begin{tabular}{ll}
\hline Substance groups & Substances \\
\hline Antihypertensives & Prazosin, doxazosin, terazosin, and clonidine \\
Atypical neuroleptics & Olanzapine, risperidone, and aripiprazole \\
Antidepressants & Trazodone, fluvoxamine, and tricyclics \\
Antihistamines & Cyproheptadine \\
Anticonvulsants & Gabapentin and topiramate \\
Synthetic cannabinoids & Nabilone \\
\hline
\end{tabular}

* Note that the evidence for all substances listed here is low ("may be used") [100].

only antipsychotic listed, but no recommendation is given due to the paucity of data.

Drug treatment of post-traumatic nightmares is a matter of controversial discussion. In recent years, prazosin ( $\alpha 1$ adrenergic receptor antagonist) has increasingly become the focus for drug treatment. Initially, randomly observed in the treatment of hypertension, the efficacy of prazosin on PTSD-associated nightmares has been shown in several randomized studies [121]. As a result, the AASM initially recommended the use of prazosin for the treatment of PTSD-associated nightmares [122]. In 2018, however, a multicenter randomized study could not confirm the favorable results [123], leading to the recommendation level being downgraded to "may be used" by the AASM [100], decision which has raised some concerns by other authors [124]. Recent meta-analyses revealed that prazosin is effective in the treatment of post-traumatic nightmares, whereas its effects on sleep quality and PTSD symptoms in general are less favorable [125, 126]. Interestingly, a recent study has shown that prazosin was associated with an increased risk of OSAS [127], finding that may help to explain why some patients do not experience an increase in their sleep quality [128]. Prazosin is not available in some European countries. Alternatively, doxazosin or terazosin (also a 1 -antagonists but with different pharmacodynamics) may be used [129]. For substances with different mechanisms of action, the evidence regarding their effectiveness in the treatment of posttraumatic nightmares is limited [100]. The pharmacological treatment of post-traumatic nightmares is summarized in Table 5.

Because there are no official recommendations for any of the substances, they should be used only following a strict risk-benefit analysis, especially considering that their use would be considered off-label. Specifically, the noradrenergic-serotonergic reuptake inhibitor venlafaxine and the benzodiazepine clonazepam exert no effect on nightmares in PTSD, and their use is explicitly discouraged [100]. It should also be taken into account that serotonergic antidepressants in particular may induce or intensify nightmares [130]. In the context of a change or adjustment of medication, it may be helpful to monitor the frequency and intensity of nightmares. Preliminary results of medically prescribed cannabis for trauma-related nightmares seem to be promising [131]; however, the evidence to date for this indication is low [132]. In the case of pharmacological treatment of sleep-related target symptoms, concomitant somatic diseases, such as arterial hypertension or neuropathic pain should also be considered to avoid polypharmacy.

\section{Integrating Sleep Disorders in a Broader PTSD- \\ Treatment Concept}

Improvement of symptoms at night might also be accompanied by an amelioration of PTSD symptoms during the day [17-19]. Conversely, residual sleep disorders may contribute to the maintenance of PTSD if they are not adequately treated $[15,16]$. Therefore, a close integration of different interventions for day and night symptoms in the sense of an integrative concept would be desirable [95]. Moreover, the implementation of specific techniques, such as CBT-I, ERRT, EMDR, and IRT in a broader PTSD-treatment concept requires adequate knowledge of corresponding methods or experience in the treatment of sleep disorders. Further studies are needed comprising medical, psychological, and sociocultural factors to establish optimized-treatment algorithms [95].

\section{Sleep Interventions in the Early Aftermath of Trauma}

Whether an early effective treatment of sleep disorders and nightmares can mitigate or even prevent the development of full PTSD remains to be clarified. However, sleep interventions after traumatic events, such as sleep facilitation and targeted sleep deprivation have been discussed 
as possible therapeutic approaches [133]. Already in 2006, theoretical considerations led to the suggestion that sleep deprivation immediately after a traumatic event could prevent the transition to PTSD [134]. Because it is rarely possible to study sleep so shortly after a traumatic event, the so-called trauma film paradigm (an experimental model for traumatic events) was developed. By exposing participants to analog trauma (film-representing traumatic experiences), researchers are able to study immediate effects of trauma and the effects of treatments on the re-experience of trauma and other PTSD symptoms [135]. Using this method, it was reported [134] that sleep deprivation immediately after an induced trauma led to fewer intrusions [136]. These findings contrast with results from another study with rare and mild intrusive memories after sleep episode following an experimental trauma [137]. A subsequent study found no significant group difference of intrusive symptoms in the week following a trauma film [138]. Additional experimental studies have demonstrated that longer REM sleep duration was associated with reduced PTSD severity, and higher REM theta activity with fewer intrusive memories [139]; furthermore, napping was associated with fewer intrusive memories [140]. Overall, these studies provide some evidence for a possible protective role of sleep after (experimentally induced) trauma in the development of intrusive symptoms and PTSD [133]. Naturalistic studies have found that sleep disorders directly following a traumatic event may increase the risk for the development and increased severity of PTSD [133]. In addition, sleep disturbances in the first week after a trauma correlated with the extent of intrusive symptoms [141]. In particular, sleep in the first night following trauma may be crucial, and both too little and too much sleep was found to promote intrusive symptoms [142]. Taken together, research on targeted sleep interventions has revealed heterogeneous results requiring further study. The use of home-based PSG immediately after a traumatic event may be a promising approach to gain further insights into the complex relationship between sleep and PTSD [51].

\section{Conclusions and Future Directions}

The present review summarizes the existing literature on the clinical features and treatment options of sleep disorders in patients with PTSD. We emphasize that sleep and PTSD are strongly interrelated in a bidirectional manner. Persistent sleep problems are an important prognostic factor for the development and severity of

Sleep Disorders in Post-Traumatic Stress Disorder
PTSD. Therefore, a targeted exploration of sleep disturbances, including the recognition of comorbid-specific sleep disorders, such as OSAS and parasomnias, is essential. As sleep disturbances may emerge as prodromes of PTSD, this applies also to people who have been exposed to a traumatic event. An effective treatment of sleep disorders and nightmares may not only improve symptoms at night but also daytime well-being and quality of life. Overall, there is robust evidence for the effectiveness of behavioral therapy methods and less evidence for pharmacological treatment. Identifying subgroups of patients with PTSD, who benefit from drug treatment to a greater extent is of great interest. In addition, integrative concepts and optimized treatment algorithms for sleep and daytime symptoms are needed. Adequate therapy might also reduce the risk of suicidality in these patients; however, the complex interactions between PTSD, sleep, and suicidality are not well understood and should be investigated in more detail. We have also reviewed the growing literature on the macro- and microstructure of sleep using PSG and quantitative high-density EEG analyses. Although promising results have been published, it still has to be clarified whether EEG spectral topologies may serve as biomarkers in PTSD. Future studies should also make efforts to clarify the effects of sleep alterations on emotional processing and traumatic memories. Specifically, experimental research can provide new insights that aim at specific sleep interventions as preventive measures for PTSD [51].

\section{Statement of Ethics}

The authors have no ethical conflicts to disclose.

\section{Conflict of Interest Statement}

The authors have no conflicts of interest to declare.

\section{Funding Sources}

The authors have no funding sources to declare.

\section{Author Contributions}

F.C.W. and T.C.W. conceptualized and wrote the first version of the manuscript. Both the authors provided significant contributions to refining the content, approved the final version, and are responsible for the integrity of this work. 


\section{References}

1 Ross RJ, Ball WA, Sullivan KA, Caroff SN. Sleep disturbance as the hallmark of posttraumatic stress disorder. Am J Psychiatry. 1989; 146:697-707.

2 American Psychiatric Association. Diagnostic and statistical manual of mental disorders. 5th ed. Arlington: American Psychiatric Publishing; 2013.

3 Richards A, Kanady JC, Neylan TC. Sleep disturbance in PTSD and other anxiety-related disorders: an updated review of clinical features, physiological characteristics, and psychological and neurobiological mechanisms. Neuropsychopharmacology. 2020;45:55-73.

4 Bryant RA, Creamer M, O’Donnell M, Silove D, McFarlane AC. Sleep disturbance immediately prior to trauma predicts subsequent psychiatric disorder. Sleep. 2010;33:69-74.

5 Gehrman P, Seelig AD, Jacobson IG, Boyko EJ, Hooper TI, Gackstetter GD, et al. Predeployment sleep duration and insomnia symptoms as risk factors for new-onset mental health disorders following military deployment. Sleep. 2013;36:1009-18.

6 Koffel E, Polusny MA, Arbisi PA, Erbes CR. Pre-deployment daytime and nighttime sleep complaints as predictors of post-deployment PTSD and depression in National Guard troops. J Anxiety Disord. 2013;27:512-9.

7 Wang HE, Campbell-Sills L, Kessler RC, Sun $\mathrm{X}$, Heeringa SG, Nock MK, et al. Pre-deployment insomnia is associated with post-deployment post-traumatic stress disorder and suicidal ideation in US Army soldiers. Sleep. 2019;42:1-9.

8 Koren D, Arnon I, Lavie P, Klein E. Sleep complaints as early predictors of posttraumatic stress disorder: a 1-year prospective study of injured survivors of motor vehicle accidents. Am J Psychiatry. 2002;159:855-7.

9 Wright KM, Britt TW, Bliese PD, Adler AB, Picchioni D, Moore D. Insomnia as predictor versus outcome of PTSD and depression among Iraq combat veterans. J Clin Psychol. 2011;67:1240-58

10 Brownlow JA, McLean CP, Gehrman PR, Harb GC, Ross RJ, Foa EB. Influence of sleep disturbance on global functioning after posttraumatic stress disorder treatment. J Trauma Stress. 2016;29:515-21.

11 Nishith P, Resick PA, Mueser KT. Sleep difficulties and alcohol use motives in female rape victims with posttraumatic stress disorder. J Trauma Stress. 2001;14:469-79.

12 Belleville G, Guay S, Marchand A. Persistence of sleep disturbances following cognitive-behavior therapy for posttraumatic stress disorder. J Psychosom Res. 2011;70:318-27.

13 Pruiksma KE, Taylor DJ, Wachen JS, Mintz J, Young-McCaughan S, Peterson AL, et al. Residual sleep disturbances following PTSD treatment in active duty military personnel. Psychol Trauma. 2016;8:697-701.

14 Larsen SE, Fleming CJE, Resick PA. Residual symptoms following empirically supported treatment for PTSD. Psychol Trauma. 2019; 11:207-15.

15 Garthus-Niegel S, Ayers S, von Soest T, Torgersen L, Eberhard-Gran M. Maintaining factors of posttraumatic stress symptoms following childbirth: a population-based, two-year follow-up study. J Affect Disord. 2015;172: 146-52.

16 Pigeon WR, Campbell CE, Possemato K, Ouimette P. Longitudinal relationships of insomnia, nightmares, and PTSD severity in recent combat veterans. J Psychosom Res. 2013;75: 546-50.

17 Galovski TE, Harik JM, Blain LM, Elwood L, Gloth C, Fletcher TD. Augmenting cognitive processing therapy to improve sleep impairment in PTSD: a randomized controlled trial. J Consult Clin Psychol. 2016;84:167-77.

18 Krakow B, Hollifield M, Johnston L, Koss M, Schrader R, Warner TD, et al. Imagery rehearsal therapy for chronic nightmares in sexual assault survivors with posttraumatic stress disorder: a randomized controlled trial. JAMA. 2001;286:537-45.

19 Pruiksma KE, Cranston CC, Rhudy JL, Micol RL, Davis JL. Randomized controlled trial to dismantle exposure, relaxation, and rescripting therapy (ERRT) for trauma-related nightmares. Psychol Trauma. 2018;10:67-75.

20 Biggs QM, Ursano RJ, Wang J, Wynn GH, Carr RB, Fullerton CS. Post traumatic stress symptom variation associated with sleep characteristics. BMC Psychiatry. 2020;20:174.

21 Milanak ME, Zuromski KL, Cero I, Wilkerson AK, Resnick HS, Kilpatrick DG. Traumatic event exposure, posttraumatic stress disorder, and sleep disturbances in a national sample of U.S. adults. J Trauma Stress. 2019; 32:14-22.

22 Colvonen PJ, Straus LD, Acheson D, Gehrman P. A review of the relationship between emotional learning and memory, sleep, and PTSD. Curr Psychiatry Rep. 2019;21:2.

23 Inman DJ, Silver SM, Doghramji K. Sleep disturbance in post-traumatic stress disorder: a comparison with non-PTSD insomnia. J Traum Stress. 1990;3(3):429-37.

24 Colvonen PJ, Straus LD, Stepnowsky C, McCarthy MJ, Goldstein LA, Norman SB. Recent advancements in treating sleep disorders in co-occurring PTSD. Curr Psychiatry Rep. 2018;20:48.

25 Werner GG, Riemann D, Ehring T. Fear of sleep and trauma-induced insomnia: a review and conceptual model. Sleep Med Rev. 2020; 55:101383.

26 Gieselmann A, Ait Aoudia M, Carr M, Germain A, Gorzka R, Holzinger B, et al. Aetiology and treatment of nightmare disorder: state of the art and future perspectives. J Sleep Res. 2019;28:e12820.

27 Mysliwiec V, Brock MS, Creamer JL, O’Reilly BM, Germain A, Roth BJ. Trauma associated sleep disorder: a parasomnia induced by trauma. Sleep Med Rev. 2018;37:94-104.
28 Phelps AJ, Kanaan RAA, Worsnop C, Redston S, Ralph N, Forbes D. An ambulatory Polysomnography Study of the post-traumatic nightmares of post-traumatic stress disorder. Sleep. 2018;41:zsx188.

29 Frase L, Acker J, Cohrs S, Danker-Hopfe H, Frohn C, Göder R, et al. Empfehlungen zur Durchführung einer Polygraphie oder Polysomnographie im Bereich Psychiatrie und Psychotherapie: positionspapier des DGPPNReferats Schlafmedizin. Nervenarzt. 2019;91: 843-53.

30 Baglioni C, Nanovska S, Regen W, Spiegelhalder K, Feige B, Nissen C, et al. Sleep and mental disorders: a meta-analysis of polysomnographic research. Psychol Bull. 2016;142:969-90.

31 Zhang Y, Ren R, Sanford LD, Yang L, Zhou J, Zhang J, et al. Sleep in posttraumatic stress disorder: a systematic review and meta-analysis of polysomnographic findings. Sleep Med Rev. 2019;48:101210.

32 Breslau N, Roth T, Burduvali E, Kapke A, Schultz L, Roehrs T. Sleep in lifetime posttraumatic stress disorder: a communitybased polysomnographic study. Arch Gen Psychiatry. 2004;61:508-16.

33 van Boxtel GJM, Cluitmans PJM, Raymann RJEM, Ouwerkerk M, Denissen AJM, Dekker $\mathrm{MKJ}$, et al. Heart rate variability, sleep, and the early detection of post-traumatic stress disorder. In: Vermetten E, Germain A, Neylan TC, editors. Sleep and combat-related post traumatic stress disorder. New York, NY: Springer New York; 2018. p. 253-63

34 Mellman TA, Knorr BR, Pigeon WR, Leiter JC, Akay M. Heart rate variability during sleep and the early development of posttraumatic stress disorder. Biol Psychiatry. 2004; 55:953-6.

35 Minassian A, Maihofer AX, Baker DG, Nievergelt CM, Geyer MA, Risbrough VB. Association of predeployment heart rate variability with risk of postdeployment posttraumatic stress disorder in active-duty marines. JAMA Psychiatry. 2015;72:979-86.

36 Kobayashi I, Lavela J, Bell K, Mellman TA. The impact of posttraumatic stress disorder versus resilience on nocturnal autonomic nervous system activity as functions of sleep stage and time of sleep. Physiol Behav. 2016; 164:11-8.

37 de Boer M, Nijdam MJ, Jongedijk RA, Bangel KA, Olff M, Hofman WF, et al. The spectral fingerprint of sleep problems in post-traumatic stress disorder. Sleep. 2020;43:zsz269.

38 Modarres MH, Opel RA, Weymann KB, Lim MM. Strong correlation of novel sleep electroencephalography coherence markers with diagnosis and severity of posttraumatic stress disorder. Sci Rep. 2019;9:4247.

39 Wang C, Ramakrishnan S, Laxminarayan S, Dovzhenok A, Cashmere JD, Germain A, et al. An attempt to identify reproducible highdensity EEG markers of PTSD during sleep. Sleep. 2020;43:zsz207. 
40 Jones S, Castelnovo A, Riedner B, Flaherty B, Prehn-Kristensen A, Benca R, et al. Sleep and emotion processing in paediatric posttraumatic stress disorder: a pilot investigation. J Sleep Res. 2021;2021:e13261.

41 Antony JW, Schönauer M, Staresina BP, Cairney SA. Sleep spindles and memory reprocessing. Trends Neurosci. 2019;42:1-3.

42 Wang C, Laxminarayan S, Ramakrishnan S, Dovzhenok A, Cashmere JD, Germain A, et al. Increased oscillatory frequency of sleep spindles in combat-exposed veteran men with post-traumatic stress disorder. Sleep. 2020; 43(10):zsaa064.

43 Wang C, Laxminarayan S, David Cashmere J, Germain A, Reifman J. Inter-channel phase differences during sleep spindles are altered in veterans with PTSD. Neuroimage Clin. 2020; 28:102390.

44 Nielsen T, Carr M, Picard-Deland C, Marquis LP, Saint-Onge K, Blanchette-Carrière C, et al. Early childhood adversity associations with nightmare severity and sleep spindles. Sleep Med. 2019;56:57-65.

45 Blaskovich B, Reicher V, Gombos F, Spoormaker VI, Simor P. Hyperarousal captured in increased number of arousal events during pre-REM periods in individuals with frequent nightmares. J Sleep Res. 2020;29:e12965.

46 Sharma R, Sahota P, Thakkar MM. Severe and protracted sleep disruptions in mouse model of post-traumatic stress disorder. Sleep. 2018; 41:zsy003.

47 Goldstein AN, Walker MP. The role of sleep in emotional brain function. Annu Rev Clin Psychol. 2014;10:679-708.

48 Wassing R, Lakbila-Kamal O, Ramautar JR, Stoffers D, Schalkwijk F, van Someren EJW. Restless REM sleep impedes overnight amygdala adaptation. Curr Biol. 2019;29:2351-8. e4.

49 Murkar ALA, De Koninck J. Consolidative mechanisms of emotional processing in REM sleep and PTSD. Sleep Med Rev. 2018;41:17384.

50 Vanderheyden WM, George SA, Urpa L, Kehoe M, Liberzon I, Poe GR. Sleep alterations following exposure to stress predict fear-associated memory impairments in a rodent model of PTSD. Exp Brain Res. 2015;233:2335-46.

51 Repantis D, Wermuth K, Tsamitros N, Danker-Hopfe H, Bublitz JC, Kühn S, et al. REM sleep in acutely traumatized individuals and interventions for the secondary prevention of post-traumatic stress disorder. Eur J Psychotraumatol. 2020;11:1740492.

52 Davis CJ, Vanderheyden WM. Optogenetic sleep enhancement improves fear-associated memory processing following trauma exposure in rats. Sci Rep. 2020;10:18025.

53 Cohen S, Kaplan Z, Zohar J, Cohen H. Preventing sleep on the first resting phase following a traumatic event attenuates anxiety-related responses. Behav Brain Res. 2017;320:4506.

54 Cohen S, Kozlovsky N, Matar MA, Kaplan Z, Zohar J, Cohen H. Post-exposure sleep depri- vation facilitates correctly timed interactions between glucocorticoid and adrenergic systems, which attenuate traumatic stress responses. Neuropsychopharmacology. 2012; 37:2388-404.

55 Krakow BJ, Ulibarri VA, Moore BA, McIver ND. Posttraumatic stress disorder and sleepdisordered breathing: a review of comorbidity research. Sleep Med Rev. 2015;24:37-45.

56 Gupta MA, Simpson FC. Obstructive sleep apnea and psychiatric disorders: a systematic review. J Clin Sleep Med. 2015;11:165-75.

57 Freed S, Craske MG, Greher MR. Nocturnal panic and trauma. Depress Anxiety. 1999;9: $141-5$.

58 Craske MG, Tsao JC. Assessment and treatment of nocturnal panic attacks. Sleep Med Rev. 2005;9:173-84.

59 Germain A, Hall M, Krakow B, Katherine Shear M, Buysse DJ. A brief sleep scale for posttraumatic stress disorder: pittsburgh sleep quality index addendum for PTSD. J Anxiety Disord. 2005;19:233-44.

60 Ross RJ, Ball WA, Dinges DF, Kribbs NB, Morrison AR, Silver SM, et al. Motor dysfunction during sleep in posttraumatic stress disorder. Sleep. 1994;17:723-32.

61 Husain AM, Miller PP, Carwile ST. Rem sleep behavior disorder: potential relationship to post-traumatic stress disorder. J Clin Neurophysiol. 2001;18:148-57.

62 Elliott JE, Opel RA, Pleshakov D, Rachakonda T, Chau AQ, Weymann KB, et al. Posttraumatic stress disorder increases the odds of REM sleep behavior disorder and other parasomnias in veterans with and without comorbid traumatic brain injury. Sleep. 2020;43: zsz237.

63 Lee E, Kim K, So HS, Choi JH, Yoon IY, Choi $H$. REM sleep behavior disorder among veterans with and without post-traumatic stress disorder. Psychiatry Investig. 2020;17:98795.

64 Yao C, Fereshtehnejad SM, Keezer MR, Wolfson C, Pelletier A, Postuma RB. Risk factors for possible REM sleep behavior disorder: a CLSA population-based cohort study. Neurology. 2018;92:e475-85.

65 Brown TM, Boudewyns PA. Periodic limb movements of sleep in combat veterans with posttraumatic stress disorder. J Trauma Stress. 1996;9:129-36.

66 El-Solh AA, Adamo D, Kufel T. Comorbid insomnia and sleep apnea in veterans with posttraumatic stress disorder. Sleep Breath. 2018; 22:23-31.

67 Orr JE, Smales C, Alexander TH, Stepnowsky C, Pillar G, Malhotra A, et al. Treatment of OSA with CPAP is associated with improvement in PTSD symptoms among veterans. J Clin Sleep Med. 2017;13:57-63.

68 Mohammadi H, Aarabi A, Rezaei M, Khazaie $\mathrm{H}$, Brand S. Sleep spindle characteristics in obstructive sleep apnea syndrome (OSAS). Front Neurol. 2021;12:598632.

69 Lam SP, Fong SY, Ho CK, Yu MW, Wing YK. Parasomnia among psychiatric outpatients: a clinical, epidemiologic, cross-sectional study. J Clin Psychiatry. 2008;69:1374-82.

70 Lam SP, Zhang J, Li SX, Wing YK. RBD, antidepressant medications, and psychiatric disorders. In: Schenck CH, Högl B, Videnovic A, editors. Rapid-eye-movement sleep behavior disorder. Cham: Springer International Publishing; 2019. p. 123-34

71 Lee K, Baron K, Soca R, Attarian H. The prevalence and characteristics of REM sleep without atonia (RSWA) in patients taking antidepressants. J Clin Sleep Med. 2016;12:351-5.

72 McCarter SJ, St Louis EK, Sandness DJ, Arndt K, Erickson M, Tabatabai G, et al. Antidepressants increase REM sleep muscle tone in patients with and without REM sleep behavior disorder. Sleep. 2015;38:907-17.

73 Mellman TA. A time to recognize trauma-related sleep disorder or a time to pause and consider? Sleep. 2020;43:zsaa069.

74 Ney LJ, Hsu CMK, Nicholson E, Zuj DV, Clark L, Kleim B, et al. The effect of self-reported REM behavior disorder symptomology on intrusive memories in post-traumatic stress disorder. Behav Sleep Med. 2020;1-14.

75 Ferri R, Koo BB, Picchietti DL, Fulda S. Periodic leg movements during sleep: phenotype, neurophysiology, and clinical significance. Sleep Med. 2017;31:29-38.

76 Yang C, White DP, Winkelman JW. Antidepressants and periodic leg movements of sleep. Biol Psychiatry. 2005;58:510-4.

77 Mysliwiec V, O’Reilly B, Polchinski J, Kwon HP, Germain A, Roth BJ. Trauma associated sleep disorder: a proposed parasomnia encompassing disruptive nocturnal behaviors, nightmares, and REM without atonia in trauma survivors. J Clin Sleep Med. 2014;10:1143-8.

78 Thordardottir EB, Hansdottir I, Valdimarsdottir UA, Shipherd JC, Resnick H, Gudmundsdottir B. The manifestations of sleep disturbances 16 years post-trauma. Sleep. 2016;39:1551-4.

79 Feemster JC, Smith KL, McCarter SJ, St Louis EK. Trauma-associated sleep disorder: a posttraumatic stress/REM sleep behavior disorder mash-up? J Clin Sleep Med. 2019;15:345-9.

80 Mysliwiec V, Brock MS, Thomas AL, Creamer JL. The extreme nocturnal manifestation of trauma: trauma associated sleep disorder. In: Vermetten E, Germain A, Neylan TC, editors. Sleep and combat-related post traumatic stress disorder. New York, NY: Springer; 2018. p. 215-25

81 Bernert RA, Kim JS, Iwata NG, Perlis ML. Sleep disturbances as an evidence-based suicide risk factor. Curr Psychiatry Rep. 2015; 17:554.

82 Liu JW, Tu YK, Lai YF, Lee HC, Tsai PS, Chen TJ, et al. Associations between sleep disturbances and suicidal ideation, plans, and attempts in adolescents: a systematic review and meta-analysis. Sleep. 2019;42:zsz054.

83 Wong MM, Brower KJ. The prospective relationship between sleep problems and suicidal behavior in the National Longitudinal Study of adolescent health. J Psychiatr Res. 2012;46: 953-9. 
84 Nadorff MR, Fiske A, Sperry JA, Petts R, Gregg JJ. Insomnia symptoms, nightmares, and suicidal ideation in older adults. J Gerontol B Psychol Sci Soc Sci. 2013;68:145-52.

85 Khazaie H, Zakiei A, McCall WV, Noori K, Rostampour M, Sadeghi Bahmani D, et al. Relationship between sleep problems and selfinjury: a systematic review. Behav Sleep Med. 2020;1-16.

86 Short NA, Ennis CR, Oglesby ME, Boffa JW, Joiner TE, Schmidt NB. The mediating role of sleep disturbances in the relationship between posttraumatic stress disorder and self-injurious behavior. J Anxiety Disord. 2015;35:6874.

87 Kang GE, Patriquin MA, Nguyen $\mathrm{H}$, Oh $\mathrm{H}$, Rufino KA, Storch EA, et al. Objective measurement of sleep, heart rate, heart rate variability, and physical activity in suicidality: a systematic review. J Affect Disord. 2020;273: 318-27.

88 Schneider M, Schwerdtfeger A. Autonomic dysfunction in posttraumatic stress disorder indexed by heart rate variability: a meta-analysis. Psychol Med. 2020;50:1937-48.

89 Song BA, Yoo SY, Kang HY, Byeon SH, Shin $\mathrm{SH}$, Hwang EJ, et al. Post-traumatic stress disorder, depression, and heart-rate variability among North Korean defectors. Psychiatry Investig. 2011;8:297-304.

90 Sareen J, Cox BJ, Stein MB, Afifi TO, Fleet C, Asmundson GJ, et al. Physical and mental comorbidity, disability, and suicidal behavior associated with posttraumatic stress disorder in a large community sample. Psychosom Med. 2007;69:242-8.

91 Krysinska K, Lester D. Post-traumatic stress disorder and suicide risk: a systematic review. Arch Suicide Res. 2010;14(1):1-23.

92 Weber FC, Norra C, Wetter TC. Sleep disturbances and suicidality in posttraumatic stress disorder: an overview of the literature. Front Psychiatry. 2020;11:167.

93 Bishop TM, Walsh PG, Ashrafioun L, Lavigne JE, Pigeon WR. Sleep, suicide behaviors, and the protective role of sleep medicine. Sleep Med. 2020;66:264-70.

94 Schäfer I, Gast U, Hofmann A, Knaevelsrud C, Lampe A, Liebermann P, et al. S3-leitlinie posttraumatische belastungsstörung. Berlin, Heidelberg: Springer Berlin Heidelberg; 2019.

95 Miller KE, Brownlow JA, Gehrman PR. Sleep in PTSD: treatment approaches and outcomes. Curr Opin Psychol. 2019;34:12-7.

96 Riemann D, Baum E, Cohrs S, Crönlein T, Hajak G, Hertenstein E, et al. S3-leitlinie nicht erholsamer schlaf/schlafstörungen. Somnologie. 2017;21(1):2-44.

97 Qaseem A, Kansagara D, Forciea MA, Cooke $\mathrm{M}$, Denberg TD. Management of chronic insomnia disorder in adults: a clinical practice guideline from the American college of physicians. Ann Intern Med. 2016;165:125-33.

98 Miller KE, Brownlow JA, Woodward S, Gehrman PR. Sleep and dreaming in posttraumatic stress disorder. Curr Psychiatry Rep. 2017; 19:71.
99 Krakow B, Zadra A. Clinical management of chronic nightmares: imagery rehearsal therapy. Behav Sleep Med. 2006;4(1):45-70.

100 Morgenthaler TI, Auerbach S, Casey KR, Kristo D, Maganti R, Ramar K, et al. Position paper for the treatment of nightmare disorder in adults: an American academy of sleep medicine position paper. J Clin Sleep Med. 2018;14:1041-55.

101 Frase L, Duss SB, Gieselmann A, Penzel T, Wetter TC, Pollmächer T. Internetbasierte kognitive Verhaltenstherapie der Insomnie und Albtraumstörung. [Internet-based cognitive behavioral therapy of insomnia and nightmare disorder]. Nervenarzt. 2019;91: 617-23.

102 Davis JL, Rhudy JL, Pruiksma KE, Byrd P, Williams AE, McCabe KM, et al. Physiological predictors of response to exposure, relaxation, and rescripting therapy for chronic nightmares in a randomized clinical trial. J Clin Sleep Med. 2011;7:622-31.

103 McDermott TJ, Lee JY, Paquet CP, Huber FA, Sitz AL, Robertson K, et al. Exposure, relaxation, and rescripting therapy could treat residual nightmares following PTSD treatment. Psychiatry Res. 2021;295: 113630.

104 Cogan CM, Lee JY, Cranston CC, Pruiksma KE, Rhudy JL, Davis JL. The impact of exposure, relaxation, and rescripting therapy for post-trauma nightmares on suicidal ideation. J Clin Psychol. 2019;75:2095-105.

105 Resick PA, Nishith P, Weaver TL, Astin $\mathrm{MC}$, Feuer CA. A comparison of cognitiveprocessing therapy with prolonged exposure and a waiting condition for the treatment of chronic posttraumatic stress disorder in female rape victims. J Consult Clin Psychol. 2002;70:867-79.

106 Shapiro F, Kaslow FW, Maxfield L. Handbook of EMDR and family therapy processes. Hoboken, NJ: Wiley; 2007.

107 Bishop TM, Britton PC, Knox KL, Pigeon WR. Cognitive behavioral therapy for insomnia and imagery rehearsal in combat veterans with comorbid posttraumatic stress: a case series. Mil Behav Health. 2016; 4:58-64.

108 Colvonen PJ, Drummond SPA, Angkaw AC, Norman SB. Piloting cognitive-behavioral therapy for insomnia integrated with prolonged exposure. Psychol Trauma. 2019; 11:107-13.

109 López CM, Lancaster CL, Wilkerson A, Gros DF, Ruggiero KJ, Acierno R. Residual insomnia and nightmares postintervention symptom reduction among veterans receiving treatment for comorbid PTSD and depressive symptoms. Behav Ther. 2019;50: 910-23.

110 Jang EH, Hong Y, Kim Y, Lee S, Ahn Y, Jeong KS, et al. The development of a sleep intervention for firefighters: the FIT-IN (Firefighter's therapy for insomnia and nightmares) Study. Int J Environ Res Public Health. 2020;17(23):8738.
111 de Macêdo TCF, Ferreira GH, de Almondes KM, Kirov R, Mota-Rolim SA. My dream, my rules: can lucid dreaming treat nightmares? Front Psychol. 2019;10:2618.

112 Holzinger B, Saletu B, Klösch G. Cognitions in sleep: lucid dreaming as an intervention for nightmares in patients with posttraumatic stress disorder. Front Psychol. 2020; 11:1826.

113 Saunders DT, Roe CA, Smith G, Clegg H. Lucid dreaming incidence: a quality effects meta-analysis of 50years of research. Conscious Cogn. 2016;43:197-215.

114 Liu Y, Xu X, Dong M, Jia S, Wei Y. Treatment of insomnia with tricyclic antidepressants: a meta-analysis of polysomnographic randomized controlled trials. Sleep Med. 2017;34:126-33.

115 Thompson W, Quay TAW, Rojas-Fernandez C, Farrell B, Bjerre LM. Atypical antipsychotics for insomnia: a systematic review. Sleep Med. 2016;22:13-7.

116 Wichniak A, Wierzbicka A, Walęcka M, Jernajczyk W. Effects of antidepressants on sleep. Curr Psychiatry Rep. 2017;19:63.

117 Doghramji K, Jangro WC. Adverse effects of psychotropic medications on sleep. Sleep Med Clin. 2016;11:503-14

118 Guina J, Rossetter SR, DeRHODES BJ, Nahhas RW, Welton RS. Benzodiazepines for PTSD: a systematic review and meta-analysis. J Psychiatr Pract. 2015;21:281-303.

119 Reuveni I, Nugent AC, Gill J, Vythilingam M, Carlson PJ, Lerner A, et al. Altered cerebral benzodiazepine receptor binding in post-traumatic stress disorder. Transl Psychiatry. 2018;8:206.

120 Sateia MJ, Buysse DJ, Krystal AD, Neubauer $\mathrm{DN}$, Heald JL. Clinical practice guideline for the pharmacologic treatment of chronic insomnia in adults: an American academy of sleep medicine clinical practice guideline. J Clin Sleep Med. 2017;13:307-49.

121 Khachatryan D, Groll D, Booij L, Sepehry AA, Schütz CG. Prazosin for treating sleep disturbances in adults with posttraumatic stress disorder: a systematic review and meta-analysis of randomized controlled trials. Gen Hosp Psychiatry. 2016;39:46-52.

122 Aurora RN, Zak RS, Auerbach SH, Casey KR, Chowdhuri S, Karippot A, et al. Best practice guide for the treatment of nightmare disorder in adults. J Clin Sleep Med. 2010;6:389-401.

123 Raskind MA, Peskind ER, Chow B, Harris C, Davis-Karim A, Holmes HA, et al. Trial of prazosin for post-traumatic stress disorder in military veterans. N Engl J Med. 2018; 378:507-17.

124 Zhang Y, Ren R, Sanford LD, Tang X. Commentary on Yücel DE et al. Downgrading recommendation level of prazosin for treating trauma-related nightmares: should decision be based on a single study? Sleep Med Rev. 2020;51:101285. 
125 Yücel DE, van Emmerik AAP, Souama C, Lancee J. Comparative efficacy of imagery rehearsal therapy and prazosin in the treatment of trauma-related nightmares in adults: a meta-analysis of randomized controlled trials. Sleep Med Rev. 2020;50: 101248.

126 Zhang Y, Ren R, Sanford LD, Yang L, Ni Y, Zhou J, et al. The effects of prazosin on sleep disturbances in post-traumatic stress disorder: a systematic review and meta-analysis. Sleep Med. 2020;67:225-31.

127 Su PL, Lin WK, Lin CY, Lin SH. Alpha-1 adrenergic-antagonist use increases the risk of sleep apnea: a Nationwide PopulationBased Cohort Study. J Clin Sleep Med. 2019; 15:1571-9.

128 McCall WV. Alpha-1 adrenergic antagonists use increases the risk of sleep apnea: implications for understanding the role of prazosin in posttraumatic stress syndrome. J Clin Sleep Med. 2020;16:643.

129 Waltman SH, Shearer D, Moore BA. Management of post-traumatic nightmares: a review of pharmacologic and nonpharmacologic treatments since 2013. Curr Psychiatry Rep. 2018;20:108.

130 Tribl GG, Wetter TC, Schredl M. Dreaming under antidepressants: a systematic review on evidence in depressive patients and healthy volunteers. Sleep Med Rev. 2013;17: $133-42$.
131 Suraev AS, Marshall NS, Vandrey R, McCartney D, Benson MJ, McGregor IS, et al. Cannabinoid therapies in the management of sleep disorders: a systematic review of preclinical and clinical studies. Sleep Med Rev. 2020;53:101339.

132 Hoch E, Niemann D, von Keller R, Schneider M, Friemel CM, Preuss UW, et al. How effective and safe is medical cannabis as a treatment of mental disorders? A systematic review. Eur Arch Psychiatry Clin Neurosci. 2019;269:87-105

133 Azza Y, Wilhelm I, Kleim B. Sleep early after trauma: a target for prevention and early intervention for posttraumatic stress disorder? Eur Psychol. 2020:1-13.

134 Wagner U, Hallschmid M, Rasch B, Born J. Brief sleep after learning keeps emotional memories alive for years. Biol Psychiatry. 2006;60:788-90.

135 James EL, Lau-Zhu A, Clark IA, Visser RM, Hagenaars MA, Holmes EA. The trauma film paradigm as an experimental psychopathology model of psychological trauma: intrusive memories and beyond. Clin Psychol Rev. 2016;47:106-42.

136 Porcheret K, Holmes EA, Goodwin GM, Foster RG, Wulff K. Psychological effect of an analogue traumatic event reduced by sleep deprivation. Sleep. 2015;38:1017-25.
137 Kleim B, Wysokowsky J, Schmid N, Seifritz E, Rasch B. Effects of sleep after experimental trauma on intrusive emotional memories. Sleep. 2016;39:2125-32.

138 Porcheret K, van Heugten-van der Kloet D, Goodwin GM, Foster RG, Wulff K, Holmes EA. Investigation of the impact of total sleep deprivation at home on the number of intrusive memories to an analogue trauma. Transl Psychiatry. 2019;9:104.

139 Sopp MR, Brueckner AH, Schäfer SK, LassHennemann J, Michael T. REM theta activity predicts re-experiencing symptoms after exposure to a traumatic film. Sleep Med. 2019;54:142-52.

140 Woud ML, Cwik JC, Blackwell SE, Kleim B, Holmes EA, Adolph D, et al. Does napping enhance the effects of cognitive bias modification-appraisal training? An experimental study. PLoS One. 2018;13:e0192837.

141 Luik AI, Iyadurai L, Gebhardt I, Holmes EA Sleep disturbance and intrusive memories after presenting to the emergency department following a traumatic motor vehicle accident: an exploratory analysis. Eur J Psychotraumatol. 2019;10:1556550.

142 Porcheret K, Iyadurai L, Bonsall MB, Goodwin GM, Beer SA, Darwent M, et al. Sleep and intrusive memories immediately after a traumatic event in emergency department patients. Sleep. 2020;43:zsaa033. 